\title{
A screening tool for the diagnosis of severe obstructive sleep Apnea in acute coronary syndrome
}

\author{
Bresson Didier $^{1 *}$, Calcaianu Georges-Daniel ${ }^{2}$, Deodati Clara ${ }^{1}$, El Nazer Tarek ${ }^{1}$, Calcaianu Mihaela ${ }^{1}$, Iamandi Carmen ${ }^{2}$ and Jacquemin \\ Laurent $^{1}$ \\ ${ }^{1}$ Department of Cardiology, Hôspital Emile Muller, France \\ ${ }^{2}$ Department of Pneumology, Hôspital Emile Muller, France
}

\begin{abstract}
Background: Obstructive sleep apnea (OSA) is a well-known cardio-vascular risk factor. However, there is no currently prominent screening strategy for its diagnosis in patients with acute coronary syndrome (ACS). The aim of this study was to establish a screening strategy for OSA in patients who present an ACS.

Methods: From January $1^{\text {st }}$ to June $30^{\text {th }} 2017$, we created a prospective cohort including all patients admitted to our Coronary Care Unit for a first myocardial infarction, without a previously-diagnosed OSA. The primary endpoint was the diagnosis of a severe OSA defined by an apnea-hypopnea index $\geq 30 / \mathrm{h}$ observed during a polysomnography performed remote from the ACS.

Results: Fifty three patients ( $60 \pm 10$ years, $81 \%$ men) were included prospectively over the study period. ST elevation myocardial infarction (STEMI) was present in $66 \%$ of cases. The primary endpoint was found in $57 \%$ of patients. Multivariate analysis identified an occluded infarct-related artery (IRA) and waist perimeter $(\mathrm{WP})$ as predictors of severe OSA (OR, 6.33, 95\% CI, 1.48-27.18, $\mathrm{p}=0.01$ and $\mathrm{OR}, 1.10,95 \% \mathrm{CI}, 1.02-1.20, \mathrm{p}=0.02$, respectively). A decision tree was established including a history of hypertension, WP and the presence of an occluded IRA, with a sensitivity of $70 \%$, a specificity of $83 \%$, a positive predictive value of $84 \%$ and a predictive negative value of $68 \%$.
\end{abstract}

Conclusion: In the present study, WP and the presence of an occluded IRA are independently associated with the presence of severe OSA. The algorithm has a good specificity for identifying patients who need to be remotely screened for OSA.

\section{Introduction}

Coronary artery disease (CAD), of which acute coronary syndrome (ACS) is the most severe manifestation, belongs to the leading causes of death in industrialized countries [1]. During the past 20 years, the management and prognosis of ACS have changed dramatically, with a decline in mortality of more than $50 \%$ [2]. In the acute phase, the development of primary angioplasty has significantly improved prognosis [3,4]. In stable CAD, identification and appropriate management of cardiovascular risk factors have slowed the progression of arteriosclerotic disease [5].

Lately, obstructive sleep apnea (OSA) syndrome has been identified as a potentially modifiable risk factor for cardiovascular disease. Observational and randomized studies performed on smallsample populations demonstrated that OSA aggravates the progression of stable coronary artery disease and promotes the occurrence of acute decompensations, such as ACS [6-10]. On the other hand, its management has a positive impact on reducing the incidence of cardiovascular events, especially coronary events [6,11-13].

Screening for OSA is especially recommended for obese and drowsy patients with stable CAD, but currently there is no validated systematic strategy in patients with ACS [14-18]. Screening is usually based on the Berlin questionnaire and on the daytime sleepiness questionnaire, as assessed by the Epworth Sleepiness Scale [19,20]. Nevertheless, these questionnaires are presently less suitable in ACS patients, who have less typical symptoms [21].
As for the screening method, although overnight oxymetry is often used in clinical practice, it does not allow evaluation of the cardiovascular response to apnea/hypopnea, and polysomnography with a continuous-lead ECG is the gold standard for the diagnosis. However, this test is expensive and sometimes not widely-available [22].

The objective of the present study was to investigate a novel noninvasive and bedside screening strategy that is less expensive and more widely applicable than standard polysomnography.

\section{Methods}

\section{Study design}

This was a prospective cohort study. Patients who presented with ACS to our single-center 20-bed Coronary Care Unit (CCU) from the 1st of January to the 30th of June 2017 were included. Patients were referred to our primary percutaneous coronary intervention (PCI) center with a diagnosis of ACS established in accordance to standard guidelines. Inclusion criteria were: age $>18$ years and the presence of

*Correspondence to: Didier B, Department of Cardiology, Hôspital Emile Muller, 20, avenue du Dr. René Laennec, 68100 Mulhouse, France, Tel: 33+389647630; Fax: 33+389647632; E-mail: didier.bresson@ghrmsa.fr

Key words: Obstructive sleep apnea, cardio-vascular, acute coronary syndrome Received: June 04, 2018; Accepted: June 14, 2018; Published: June 16, 2018 
ongoing symptoms for less than 12 hours. Exclusion criteria were: past medical history of ACS or OSA, hemodynamic instability, inability to perform a future polysomnography test (dementia, bedridden patient, any legal protection measure) and inability to obtain an informed consent. All patients underwent systematic OSA screening with a polysomnography test performed during an out-of-hospital admission, two months after the primary PCI. The primary endpoint was the presence of a severe OSA, defined as an apnea-hypopnea index (AHI) $\geq 30 /$.

All patients gave written informed consent for the procedures and research protocol, which was approved by an independent ethics committee. (CEPRO 2017-044 of the French-speaking Society of Pneumonology.)

\section{Data collection}

At admission ACS was diagnosed according to the current guidelines [14,15]. Additional data were also collected: associated diseases, cardio-vascular risk factors, anthropometric data (weight, height, neck circumference, WP, body mass index-BMI). The following validated scores were recorded at admission: Epworth Sleepiness Scale (ESS) [23,24], Berlin Questionnaire for the evaluation of OSA probability [20] and the Pittsburgh Sleep Quality Index (PSQI) score which evaluates the quality of sleep [25].

During hospitalization, echocardiographic and angiographic data (culprit coronary artery, angiographic flow assessed by TIMI score) were recorded. An occluded IRA was defined by a pre-PCI TIMI flow grade $0-1$. Coronary angiograms and the SYNTAX score were verified by 2 independent operators.

\section{Sleep study}

After the first hospital admission, all polysomnographies were performed using an Cidelec device (CID102L8D) by three dedicated and trained practitioners. The following paraclinical test were perfomed: electroencephalograms, submental electromyogram, electrocardiograms, chest and abdominal movement recording using respiratory effort bands, body position monitoring, oronasal airflow monitoring using a flow-sensor, and arterial oxygen haemoglobin saturation monitoring using a pulse oximeter. Scoring criteria for the respiratory events were in accordance to standard guidelines [26]. The AHI was calculated by dividing the number of the episodes of apnea and hypopnea by total sleep time (TST). An obstructive apnea/hypopnea and the severity of the OSA were defined according to the current cut off levels (AHI of 5-15 = mild OSA, AHI of 15-30 = moderate OSA, AHI $>30$ - severe OSA) [27-29].

The oxygen desaturation index (ODI) was defined as the hourly average number of desaturation episodes. The severity of these desaturation episodes were characterized by the time spent with oxygen saturation $<90$ percent $(\mathrm{T}<90 \%)$. It is expressed in minutes or percent when divided by TST. The number of periodic leg movements per hour and the micro-awakenings index (micro-awakenings per hour) were also collected. Follow-up data at 6 months were collected by telephone call either directly from the patient, of from the attending physician or cardiologist. Recorded events were: death, recurrence of ACS, occurrence of atrial fibrillation and stroke.

\section{Statistical analysis}

Values are presented as mean \pm standard deviation (SD) or number (\%), as appropriate. Univariate comparisons were performed using
Mann-Whitney U test for continuous variables and Chi-2 or Fisher's exact test for categorical variables, as appropriate.The independent contribution to the presence of a severe OSA by parameters recorded at admission and during hospital stay was analyzed by a backward stepwise multivariate analysis using a binary logistic regression model.

The dependent variable was the diagnosis of a severe OSA defined as $\mathrm{AHI} \geq 30$.

Predictor variables were all variables with $p$ values of less than 0.10 in the univariate regression analysis, as well as those with a known association with a severe OSA (i.e. age and diabetes) were forced in the model.

We set the $\mathrm{p}$ value $>0.10$ to eliminate confounding factors from the regression equation.Odds Ratios (OR) were estimated with $95 \%$ confidence intervals $(95 \% \mathrm{CI})$.

$\mathrm{R}$ software version 3.3.0 was used for all analysis. The $\mathrm{R}$ module of the $\mathrm{R}$ software was used to create a classification tree. The variables included in the model were the same as those used for the multivariate analysis.

A p value $<0.05$ was considered statistically significant.

\section{Results}

\section{Population}

During the study period, 136 patients were referred to our CCU for primary PCI in a context of an ACS $<12$ hours. Of these patients, 53 patients were able to undergo complete polysomnography remote from hospitalization (Figure 1). Among them, 30 (57\%) had severe OSA. Baseline characteristics are shown in Table 1. The mean age was $60 \pm 10$ years, with a large predominance of male sex (81\%). The mean BMI was $28 \pm 4 \mathrm{~kg} / \mathrm{m}^{2}$; less than $20 \%$ of patients had diabetes mellitus.

\section{ACS}

ACS-related data are presented in Table 2. Almost 2/3 of the ACS were STEMI, with no significant difference in the severity of the OSA.

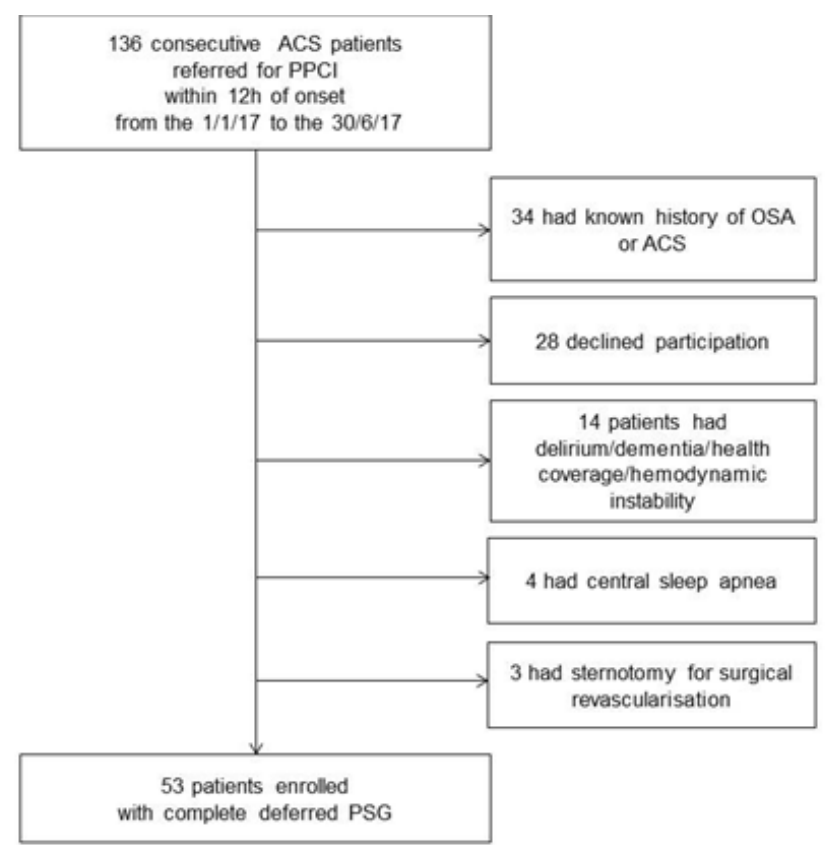

Figure 1. Patient selection procedure. 
Didier B (2018) A screening tool for the diagnosis of severe obstructive sleep Apnea in acute coronary syndrome

Table 1. Baseline characteristics of patients according to the diagnosis of severe OSA; Data are expressed as mean \pm SD or number (\%). CAD indicates coronary artery disease; COPD, Chronic obstructive pulmonary disease; ESS, Epworth Sleepiness Scale; PSQI, Pittsburgh Sleep Quality Index; BP, blood pressure; EF, left ventricular ejection fraction.

\begin{tabular}{|c|c|c|c|c|}
\hline & Overall $(n=53)$ & Severe OSA $(n=30)$ & Non-severe OSA $(n=23)$ & p-value \\
\hline Age, $y$ & $60 \pm 10$ & $61 \pm 10$ & $58 \pm 9$ & 0.2 \\
\hline Male gender & $43(81)$ & $25(83)$ & $18(78)$ & 0.73 \\
\hline BMI, $\mathrm{kg} / \mathrm{m}^{2}$ & $28 \pm 4$ & $29 \pm 4$ & $28 \pm 4$ & 0.22 \\
\hline Neck circumference, $\mathrm{cm}$ & $41 \pm 3$ & $41 \pm 3$ & $41 \pm 3$ & 0.28 \\
\hline Waist circumference, $\mathrm{cm}$ & $106 \pm 10$ & $109 \pm 10$ & $102 \pm 9$ & 0.01 \\
\hline \multicolumn{5}{|l|}{ Cardiovascular risk factors } \\
\hline Hypertension & $20(38)$ & $15(50)$ & $5(22)$ & 0.05 \\
\hline Diabete mellitus & $9(17)$ & $6(20)$ & $3(13)$ & 0.72 \\
\hline Dyslipidemia & $22(42)$ & $12(40)$ & $10(44)$ & 1 \\
\hline Current smoker & $24(45)$ & $14(47)$ & $10(44)$ & 0.8 \\
\hline \multicolumn{5}{|l|}{ Comorbidities } \\
\hline Known CAD & $11(21)$ & $7(23)$ & $4(18)$ & 0.74 \\
\hline Previous stroke & $3(5)$ & $2(7)$ & $1(5)$ & 0.24 \\
\hline Known peripheral artery disease & $5(9)$ & $2(7)$ & $3(4)$ & 0.47 \\
\hline COPD & $2(4)$ & $1(3)$ & $1(4)$ & 1 \\
\hline \multicolumn{5}{|l|}{ Sleep-related factors } \\
\hline ESS score & $7 \pm 4$ & $7 \pm 4$ & $6 \pm 3$ & 0.2 \\
\hline Berlin Questionnaire >1 & $23(43)$ & $16(53)$ & $7(30)$ & 0.16 \\
\hline PSQI score & $6 \pm 3$ & $6 \pm 3$ & $6 \pm 3$ & 0.73 \\
\hline \multicolumn{5}{|l|}{ Vital signs at admission } \\
\hline Heart rate, beats.min ${ }^{-1}$ & $75 \pm 13$ & $75 \pm 13$ & $75 \pm 12$ & 0.93 \\
\hline Systolic BP, mmHg & $134 \pm 22$ & $135 \pm 22$ & $133 \pm 22$ & 0.88 \\
\hline SpO2, \% & $97 \pm 2$ & $97 \pm 2$ & $96 \pm 3$ & 0.19 \\
\hline Killip class I & $48(91)$ & $27(90)$ & $21(91)$ & 1 \\
\hline \multicolumn{5}{|l|}{ Laboratory results } \\
\hline Peak troponin I, ng/mL & $45 \pm 52$ & $51 \pm 32$ & $36 \pm 34$ & 0.8 \\
\hline NT-proBNP, ng/mL & $1407(2660)$ & 1498(3104) & $1288(2000)$ & 0.65 \\
\hline Creatinine, $\mu \mathrm{mol} / \mathrm{L}$ & $80 \pm 19$ & $82 \pm 21$ & $75 \pm 15$ & 0.16 \\
\hline HbA1c, \% & $6.4 \pm 1.3$ & $6.5 \pm 1.5$ & $6.2 \pm 0.9$ & 0.36 \\
\hline Low-density lipoprotein, g/L & $1.3 \pm 0.5$ & $1.3 \pm 0.5$ & $1.3 \pm 0.4$ & 0.87 \\
\hline \multicolumn{5}{|l|}{ Echocardiography } \\
\hline LVEF, \% & $56 \pm 10$ & $56 \pm 10$ & $57 \pm 9$ & 0.77 \\
\hline
\end{tabular}

Table 2. Acute coronary syndrome and procedural characteristics according to the diagnosis of severe OSA; Data are expressed as mean \pm SD or number (\%). ACS indicates acute coronary syndrome; STEMI, ST elevation myocardial infarction; NSTEMI, non ST elevation myocardial infarction; UA, unstable angina; LAD, left anterior descending artery; LCx, left circumflex artery; right coronary artery; PCI, percutaneous coronary intervention.

\begin{tabular}{|c|c|c|c|c|}
\hline & Overall $(n=53)$ & Severe OSA $(n=30)$ & Non-severe OSA $(n=23)$ & p-value \\
\hline Type of ACS & & & & 0.51 \\
\hline STEMI & $35(66)$ & $19(63)$ & $16(69)$ & \\
\hline NSTEMI & $15(28)$ & $10(33)$ & $5(22)$ & \\
\hline UA & $3(6)$ & $1(4)$ & $2(9)$ & \\
\hline Infarct-related artery & & & & 0.42 \\
\hline LAD & $25(47)$ & $12(40)$ & $13(58)$ & \\
\hline LCx & $12(23)$ & $7(23)$ & $5(21)$ & \\
\hline RCA & $16(30)$ & $11(37)$ & $5(21)$ & \\
\hline Number of diseased vessels & & & & 0.4 \\
\hline 1 & $25(47)$ & $13(43)$ & $12(52)$ & \\
\hline 2 & $19(36)$ & $13(43)$ & $6(26)$ & \\
\hline 3 & $9(17)$ & $4(14)$ & $5(21)$ & \\
\hline SYNTAX score & $12(9)$ & $14(11)$ & & 0.19 \\
\hline Pre-PCI TIMI flow grade 0-1 & $23(43)$ & $17(57)$ & $6(26)$ & 0.049 \\
\hline Stenting & $50(94)$ & $27(90)$ & $22(97)$ & 0.81 \\
\hline Post-PCI TIMI flow grade 2-3 & $52(98)$ & $29(97)$ & $23(100)$ & 1 \\
\hline
\end{tabular}


The left anterior descending artery was responsible for the infarction in nearly half of the cases. Angiographic analysis revealed mostly single vessel disease with a mean SYNTAX score of $12 \pm 9$. The artery was occluded in $43 \%$ of cases.

\section{Polysomnography}

All patients underwent complete polysomnography at $69 \pm 12$ days from PCI. The mean ESS was $<11(7 \pm 4)$. Figure 2 shows the distribution of AHI in the studied population. The mean AHI was $34 / \mathrm{h} \pm 16$, with an apnea index of $15 / \mathrm{h} \pm 15$. Regarding cortical repercussion and sleep fragmentation, the micro-awakening index was $19 / \mathrm{h} \pm 13$ with $15 / \mathrm{h} \pm$ 16 periodic leg movements per hour. Concerning intermittent hypoxia, the ODI was $22 / \mathrm{h} \pm 16$ with a $\mathrm{T}<90 \%$ (minutes, percentage) at $30 \pm 44$ min and $10 \pm 17 \%$ of TST.

\section{Outcomes}

Of the 30 patients with severe OSA, 27 (90\%) received continuous positive airway pressure (CPAP) treatment and two patients a mandibular advancement device. According to data collected at 6 months, the recurrence of ACS was $2 \%$. There was no other adverse event.

\section{Univariate, multivariate analysis and the decision tree}

In univariate analysis (Table 3), a history of hypertension, WP, and the finding of an occluded artery on angiography were related to the presence of a severe OSA. The BMI, the Berlin Questionnaire and the SYNTAX score were not related to the primary endpoint (Respectively OR, 1.10, 95\% CI 0.95-1.26, $\mathrm{p}=0.21$, OR, 2.92, 95\% CI 0.89-9.58, $\mathrm{p}=$ 0.08 and OR, $1.05,95 \%$ CI $0.98-1.30, p=0.20)$. After adjusting for age and diabetes, forced variables in the multivariate backward stepwise regression model, only WP and the presence of an occluded artery on coronary angiography were associated with the diagnosis of a severe OSA. (Respectively OR, 1.10, 95\% CI, 1.02-1.20, $\mathrm{p}=0.02$ and OR, 6.33, 95\% CI, 1.48-27.18, $\mathrm{p}=0.01$ ).

Figure 3 shows the classification tree that allows the prediction of the primary endpoint, taking into account age, a history of hypertension, a history of diabetes, WP, and the presence of an occluded IRA at coronary angiography. Only WP, a history of arterial hypertension and TIMI flow of the ACS artery were eventually selected

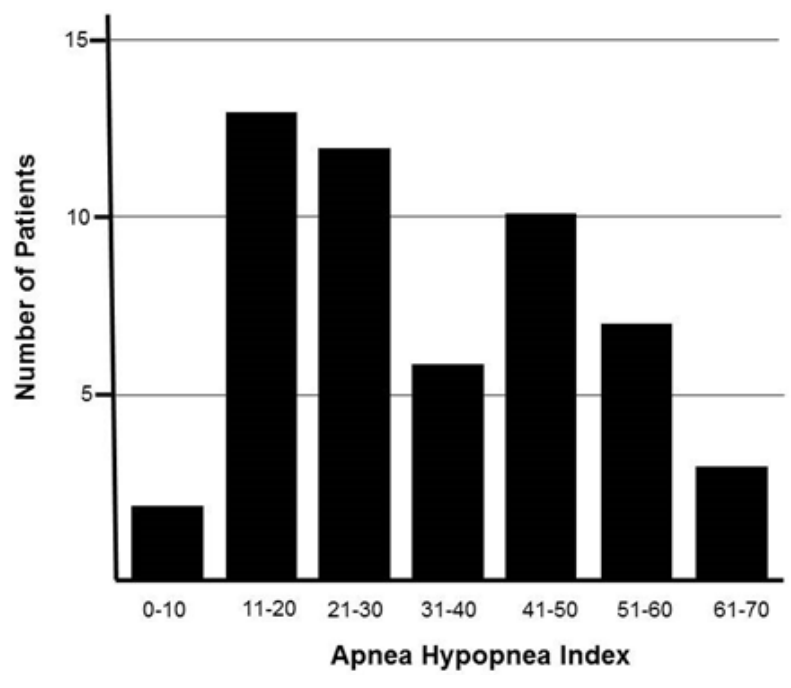

Figure 2. Distribution of Apnea-hypopnea index among 53 study patients.

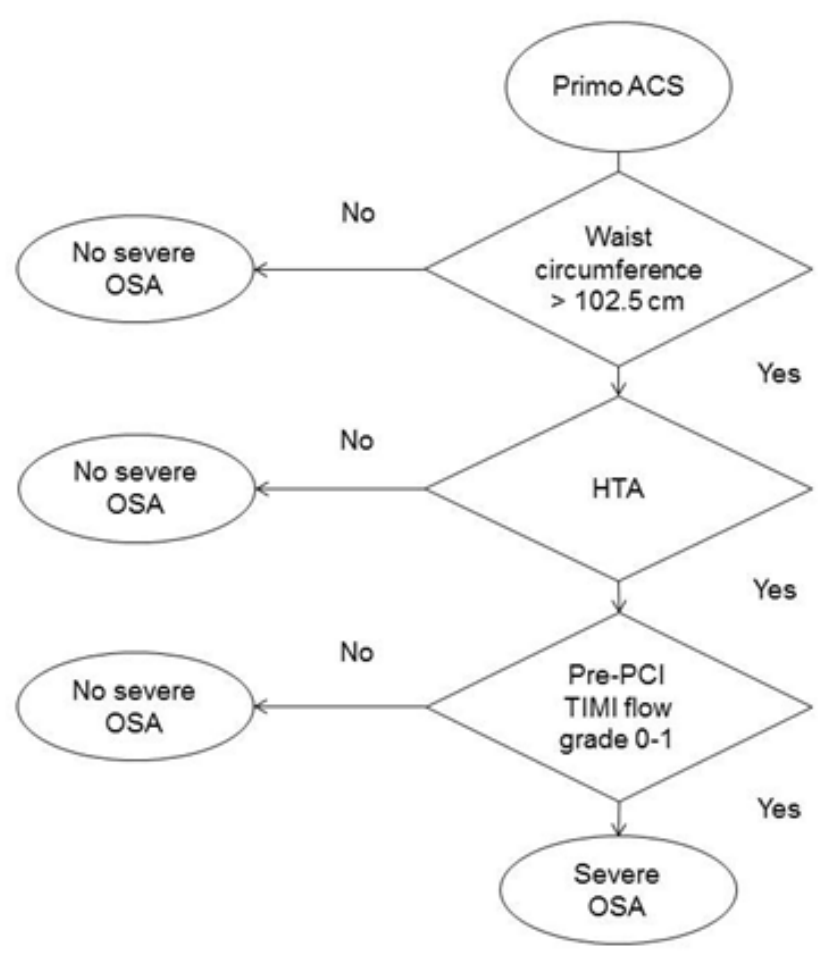

Figure 3. Cart decision tree for the screening of severe OSA among 53 patients sample.

as relevant variables. The present classification tree was able to exclude the primary endpoint for patients with a waist perimeter $\leq 102.5 \mathrm{~cm}$. It also predicted the absence of the main criterion for patients with a waist perimeter $>102.5 \mathrm{~cm}$ but without a history of hypertension or an occluded IRA. It predicted the presence of the primary endpoint for WP $>102.5 \mathrm{~cm}$ with hypertension, and for patients without hypertension but with an occluded IRA. The sensitivity of the model is $70 \%$ and its specificity $83 \%$. The positive predictive value is $84 \%$ and the negative predictive value is $68 \%$.

\section{Discussion}

The main result of the present study is that WP and an occluded IRA are independently associated with severe OSA. In cases where WP is $>102.5 \mathrm{~cm}$, along with a history of hypertension and an occluded IRA, the regression tree gives a bedside clinical tool while predicting a severe OSA with a specificity $>80 \%$.

The presence of a severe OSA defined by an IAH $\geq 30$ was found in $57 \%$ of cases. In patients with ACS, depending on the IAH cut-off value, the prevalence of OSA ranges from $37 \%$ to $66 \%[28,30]$. Our choice of a primary endpoint with an AHI threshold $\geq 30$ is relevant for several reasons. The deleterious effects of OSA on coronary artery disease are only found in patients with severe OSA (IAH $\geq 30$ ), a finding demonstrated in a cohort of over 4000 patients [31]. It is also from this level of severity that the recovery of the left ventricular ejection fraction after an ACS is impaired [32]. Finally, although the dose-response effect of CPAP treatment is not fully established, it is difficult to believe that an asymptomatic patient will tolerate $\geq 4 \mathrm{~h}$ / night of treatment [33].

Some of the classic characteristics of the OSA phenotype are found in our cohort, such as a history of hypertension and an increased abdominal perimeter. Hypertension can be explained by the vascular response to OSA-related sympathetic hyperactivation via intermittent hypoxia and sleep fragmentation [34]. Similarly, visceral obesity is a 
Table 3. Predictors of severe OSA in patients with acute coronary syndrome.

\begin{tabular}{|c|c|c|c|c|c|c|}
\hline & & Univariate & & Multivariate & \\
\hline Age & Odds Ratio & $\mathbf{9 5 \%}$ CI & p-value & Odds Ratio & 95\% CI & p-value \\
\hline Diabete mellitus & 1.04 & $0.98-1.10$ & 0.2 & 1.07 & $0.99-1.16$ & 0.1 \\
\hline HTA & 1.67 & $0.37-7.53$ & 0.51 & 0.62 & $-10-3.81$ & - \\
\hline Waist perimeter & 3.6 & $1.06-12.22$ & 0.04 & - & $1.02-1.20$ & - \\
\hline $\begin{array}{c}\text { Baseline TIMI, flow } \\
\text { grade 0-1 }\end{array}$ & 1.1 & $1.01-1.18$ & 0.02 & 1.1 & 0.02 \\
\hline
\end{tabular}

known aggravating factor of OSA, especially through the reduction of upper airway size caused by tongue fat $[35,36]$. On the other hand, a history of diabetes was only found in $17 \%$ of cases in our series, while the prevalence of diabetes is closer to $25 \%$ for STEMI American population [14] In several reported series, diabetes is an independent risk factor of OSA $[30,37,38]$. However, this fact was taken into account in our study, and a multivariate model adjusted for diabetes was used.

A significant finding is the strong link between a baseline TIMI flow grade 0-1 and a severe OSA. The TIMI flow before primary angioplasty is related to the final size of the infarct [39]. In the setting of ACS revascularized by primary PCI, Buchner et al. reported that OSA was also associated with a larger infarction size at 3 months [13] Some preclinical studies have demonstrated the impact of OSA on increased platelet aggregation, hypercoagulability and endothelial dysfunction [40-42] This could account for why an arterial occlusion is more common in severe OSA. However, the impact of OSA on the infarct size is debated. By exposure to repeated nocturnal desaturations, the myocardium could be preconditioned, resulting in a reduction in the size of the infarct [43]. Thus, the $\mathrm{T}<90 \%$ but not the AHI would appear as predictor of adverse cardiovascular outcomes in a large cohort of more than 10,000 patients [27]. A possible explanation for these divergent observations could be the presence or absence of a collateral flow when the artery is occluded. Indeed, it is one of the major determinants of the size of the infarct [44]. In our series on 20 occluded arteries, very few were collateralized (3 patients data not shown).

Regarding the screening strategy proposed in our study, it is based on an average time of 2 months between the primary-PCI and the polysomnography. The delay between PCI and polysomnography ranged from 43 to $72 \mathrm{hrs}$ in most OSA studies in the setting of an ACS $[28,43,45]$. Kosuke, et al. report a significant decrease in AHI between the acute phase of the ACS and the chronic phase (day14) [46]. OSA and ACS have an obvious but unequivoqual correlation since the OSA may also exacerbate pre-existing CAD $[47,48]$ Finally, various factors can bias the polysomnographic evaluation in the acute state, such as concomitant medications and heart failure.

We acknowledge that our study has some limitations. Our study was carried out in a single centre on a limited population sample. Another limitation is the fact that the prevalence of diabetes found in our study was lower than in other OSA studies carried out in the setting of an ACS. However, our population included patients with a first episode of myocardial infarction. The proposed strategy from the current study needs to be tested on a larger population of patients to confirm our findings

\section{Conclusion}

Waist perimeter and an occluded IRA are independently associated with severe OSA in patients presenting with a first ACS without prior known OSA. To our knowledge, our study is the first to propose a screening strategy with a remote polysomnography in patients with WP $>102.5 \mathrm{~cm}$, a history of hypertension, and an occluded IRA.
The proposed regression tree provides a bedside clinical tool while predicting a severe OSA with a specificity $>80 \%$.

\section{References}

1. Hartley A, Marshall DC, Salciccioli JD, Sikkel MB, Maruthappu M, et al. (2016) Trends in Mortality From Ischemic Heart Disease and Cerebrovascular Disease in Europe: 1980 to 2009. Circulation 133: 1916-1926. [Crossref]

2. Puymirat E, Simon T, Cayla G, Cottin Y, Elbaz M, et al. (2017) Acute Myocardial Infarction: Changes in Patient Characteristics, Management, and 6-Month Outcomes Over a Period of 20 Years in the FAST-MI Program (French Registry of Acute STElevation or Non-ST-Elevation Myocardial Infarction) 1995 to 2015. Circulation. 136: 1908-1919.

3. Puymirat E, Simon T, Steg PG, Schiele F, Guéret P, et al. (2012) Association of changes in clinical characteristics and management with improvement in survival among patients with ST-elevation myocardial infarction. JAMA 308: 998-1006.

4. Puymirat E, Schiele F, Steg PG, Blanchard D, Isorni MA, et al. (2014) Determinants of improved one-year survival in non-ST-segment elevation myocardial infarction patients: insights from the French FAST-MI program over 15 years. Int J Cardiol 177: 281-286.

5. Smith SC, Benjamin EJ, Bonow RO, Braun LT, Franklin BA, et al. (2011) AHA/ACCF Secondary Prevention and Risk Reduction Therapy for Patients with Coronary and other Atherosclerotic Vascular Disease: 2011 update: a guideline from the American Heart Association and American College of Cardiology Foundation. Circulation 124: 2458-2473.

6. Milleron O, Pillière R, Foucher A, de Roquefeuil F, Aegerter P (2004) Benefits of obstructive sleep apnoea treatment in coronary artery disease: a long-term follow-up study. Eur Heart $J$ 25: 728-734. [Crossref]

7. Mooe T, Franklin KA, Holmström K, Rabben T, Wiklund U (2001) Sleep-disordered breathing and coronary artery disease: long-term prognosis. Am J Respir Crit Care Med 164: 1910-1913. [Crossref]

8. Hung J, Whitford EG, Parsons RW, Hillman DR (1990) Association of sleep apnoea with myocardial infarction in men. Lancet 336: 261-264. [Crossref]

9. Sorajja D, Gami AS, Somers VK, Behrenbeck TR, Garcia-Touchard A (2008) Independent association between obstructive sleep apnea and subclinical coronary artery disease. Chest 133: 927-933. [Crossref]

10. Lee CH, Sethi R, Li R, Ho HH, Hein T, et al. (2016) Obstructive Sleep Apnea and Cardiovascular Events After Percutaneous Coronary Intervention. Circulation 133: 2008-2017.

11. Doherty LS, Kiely JL, Swan V, McNicholas WT (2005) Long-term effects of nasal continuous positive airway pressure therapy on cardiovascular outcomes in sleep apnea syndrome. Chest 127: 2076-2084.

12. Marin JM, Carrizo SJ, Vicente E, Agusti AGN (2005) Long-term cardiovascular outcomes in men with obstructive sleep apnoea-hypopnoea with or without treatment with continuous positive airway pressure: an observational study. Lancet Lond Engl 365:1046-1053.

13. Buchner S, Satzl A, Debl K, Hetzenecker A, Luchner A, et al. (2014) Impact of sleepdisordered breathing on myocardial salvage and infarct size in patients with acute myocardial infarction. Eur Heart J 35: 192-199.

14. O'Gara PT, Kushner FG, Ascheim DD, Casey DE, Chung MK, et al. (2013) 2013 ACCF/AHA guideline for the management of ST-elevation myocardial infarction: executive summary: a report of the American College of Cardiology Foundation American Heart Association Task Force on Practice Guidelines. Circulation 127: 529-555.

15. Amsterdam EA, Wenger NK, Brindis RG, Casey DE, Ganiats TG, et al. (2014) 2014 AHA/ACC guideline for the management of patients with non-ST-elevation acute coronary syndromes: executive summary: a report of the American College of Cardiology/American Heart Association Task Force on Practice Guidelines. Circulation 130: 2354-2394. 
16. Ibanez B, James S, Agewall S, Antunes MJ, Bucciarelli-Ducci C, et al. (2018) 2017 ESC Guidelines for the management of acute myocardial infarction in patients presenting with ST-segment elevation: The Task Force for the management of acute myocardial infarction in patients presenting with ST-segment elevation of the European Society of Cardiology (ESC). Eur Heart J 39: 119-177.

17. Roffi M, Patrono C, Collet JP, Mueller C, Valgimigli M, et al. (2016) 2015 ESC Guidelines for the management of acute coronary syndromes in patients presenting without persistent ST-segment elevation: Task Force for the Management of Acute Coronary Syndromes in Patients Presenting without Persistent ST-Segment Elevation of the European Society of Cardiology (ESC). Eur Heart J 37: 267-315.

18. Montalescot G, Sechtem U, Achenbach S, Andreotti F, Arden C (2013) 2013 ESC guidelines on the management of stable coronary artery disease: the Task Force on the management of stable coronary artery disease of the European Society of Cardiology. Eur Heart J 34: 2949-3003.

19. Piepoli MF, Hoes AW, Agewall S, Albus C, Brotons C, et al. (2016) 2016 European Guidelines on cardiovascular disease prevention in clinical practice: The Sixth Joint Task Force of the European Society of Cardiology and Other Societies on Cardiovascular Disease Prevention in Clinical Practice (constituted by representatives of 10 societies and by invited experts) Developed with the special contribution of the European Association for Cardiovascular Prevention \& Rehabilitation (EACPR). Eur Heart J 37: 2315-2381.

20. Netzer NC, Stoohs RA, Netzer CM, Clark K, Strohl KP (1999) Using the Berlin Questionnaire to identify patients at risk for the sleep apnea syndrome. Ann Intern Med 131: 485-491. [Crossref]

21. Drager LF, McEvoy RD, Barbe F, Lorenzi-Filho G, Redline S, (2017) INCOSACT Initiative (International Collaboration of Sleep Apnea Cardiovascular Trialists). Sleep Apnea and Cardiovascular Disease: Lessons From Recent Trials and Need for Team Science. Circulation 136: 1840-1850.

22. Somers VK, White DP, Amin R, Abraham WT, Costa F, et al. (2008) Sleep apnea and cardiovascular disease: an American Heart Association/american College of Cardiology Foundation Scientific Statement from the American Heart Association Council for High Blood Pressure Research Professional Education Committee, Council on Clinical Cardiology, Stroke Council, and Council On Cardiovascular Nursing. In collaboration with the National Heart, Lung, and Blood Institute National Center on Sleep Disorders Research (National Institutes of Health). Circulation 118: 1080-1011.

23. Johns MW (1991) A new method for measuring daytime sleepiness: the Epworth sleepiness scale. Sleep 14: 540-545.

24. Johns MW (1993) Daytime sleepiness, snoring, and obstructive sleep apnea. The Epworth Sleepiness Scale. Chest 103: 30-36.

25. Buysse DJ, Reynolds CF, Monk TH, Berman SR, Kupfer DJ (1989) The Pittsburgh Sleep Quality Index: a new instrument for psychiatric practice and research. Psychiatry Res 28: 193-213.

26. Berry RB, Budhiraja R, Gottlieb DJ, Gozal D, Iber C, et al. (2012) Rules for scoring respiratory events in sleep: update of the 2007 AASM Manual for the Scoring of Sleep and Associated Events. Deliberations of the Sleep Apnea Definitions Task Force of the American Academy of Sleep Medicine. J Clin Sleep Med 8: 597-619.

27. Kendzerska T, Gershon AS, Hawker G, Leung RS, Tomlinson G (2014) Obstructive sleep apnea and risk of cardiovascular events and all-cause mortality: a decade-long historical cohort study. PLoS Med 11: e1001599.

28. Hein T, Loo G, Ng WY, Tai BC, Kajiya T, et al (2013) Relationship between apnoeahypopnoea index and angiographic coronary disease phenotypes in patients presenting with acute myocardial infarction. Acute Card Care 15: 26-33.

29. Jaffe LM1, Kjekshus J, Gottlieb SS (2013) Importance and management of chronic sleep apnoea in cardiology. Eur Heart J 34: 809-815. [Crossref]
30. Lee CH, Khoo SM, Tai BC, Chong EY, Lau C, et al. (2009) Obstructive sleep apnea in patients admitted for acute myocardial infarction: Prevalence, predictors, and effect on microvascular perfusion. Chest 35: 1488-1495.

31. Gottlieb DJ, Yenokyan G, Newman AB, O'Connor GT, Punjabi NM, et al. (2010) Prospective study of obstructive sleep apnea and incident coronary heart disease and heart failure: the sleep heart health study. Circulation 122: 352-360.

32. Nakashima H, Katayama T, Takagi C, Amenomori K, Ishizaki M, et al. (2006) Obstructive sleep apnoea inhibits the recovery of left ventricular function in patients with acute myocardial infarction. Eur Heart J 27: 2317-2322.

33. McEvoy RD, Antic NA, Heeley E, Luo Y, Ou Q (2016) CPAP for Prevention of Cardiovascular Events in Obstructive Sleep Apnea. N Engl J Med 375: 919-931. [Crossref]

34. Drager LF, Polotsky VY, O’Donnell CP, Cravo SL, Lorenzi-Filho G, et al. (2015) Translational approaches to understanding metabolic dysfunction and cardiovascular consequences of obstructive sleep apnea. Am J Physiol Heart Circ Physiol 309: 1101-1111.

35. Kritikou I, Basta M, Tappouni R, Pejovic S, Fernandez-Mendoza J (2013) Sleep apnoea and visceral adiposity in middle-aged male and female subjects. Eur Respir J 41: 601 609. [Crossref]

36. Kim AM, Keenan BT, Jackson N, Chan EL, Staley B (2014) Tongue fat and its relationship to obstructive sleep apnea. Sleep 37: 1639-1648. [Crossref]

37. West SD, Nicoll DJ, Stradling JR (2006) Prevalence of obstructive sleep apnoea in men with type 2 diabetes. Thorax 61: 945-950. [Crossref]

38. Young T, Peppard PE, Gottlieb DJ (2002) Epidemiology of obstructive sleep apnea: a population health perspective. Am J Respir Crit Care Med 165: 1217-1239. [Crossref]

39. De Luca G, Ernst N, Zijlstra F, van 't Hof AWJ, Hoorntje JCA, et al. (2004) Preprocedural TIMI flow and mortality in patients with acute myocardial infarction treated by primary angioplasty. J Am Coll Cardiol 43: 1363-1367.

40. Sanner BM, Konermann M, Tepel M, Groetz J, Mummenhoff C (2000) Platele function in patients with obstructive sleep apnoea syndrome. Eur Respir J 16: 648-652. [Crossref]

41. Peled N, Kassirer M, Kramer MR, Rogowski O, Shlomi D (2008) Increased erythrocyte adhesiveness and aggregation in obstructive sleep apnea syndrome. Thromb Res 121: 631-636. [Crossref]

42. Jelic S, Padeletti M, Kawut SM, Higgins C, Canfield SM, et al. (2008) Inflammation, oxidative stress, and repair capacity of the vascular endothelium in obstructive sleep apnea. Circulation 117: 2270-2278.

43. Shah N, Redline S, Yaggi HK, Wu R, Zhao CG, et al. (2013) Obstructive sleep apnea and acute myocardial infarction severity: ischemic preconditioning? Sleep Breath Schlaf Atm 17: 819-826.

44. Mewton N, Elbaz M, Piot C, Ovize M (2011) Infarct size reduction in patients with STEMI: why we can do it. J Cardiovasc Pharmacol Ther 16: 298-303. [Crossref]

45. Mehra R, Principe-Rodriguez K, Kirchner HL, Strohl KP (2006) Sleep apnea in acute coronary syndrome: high prevalence but low impact on 6-month outcome. Sleep Med 7: $521-528$.

46. Tsukamoto K, Ohara A (2006) Temporal worsening of sleep-disordered breathing in the acute phase of myocardial infarction. Circ J Off J Jpn Circ Soc 70: 1553-1556.

47. Yumino D, Tsurumi Y, Takagi A, Suzuki K, Kasanuki H (2007) Impact of obstructive sleep apnea on clinical and angiographic outcomes following percutaneous coronary intervention in patients with acute coronary syndrome. Am J Cardiol 99: 26-30.

48. Milleron O, Pillière R, Foucher A, de Roquefeuil F, Aegerter P, et al. (2004) Benefits of obstructive sleep apnoea treatment in coronary artery disease: a long-term follow-up study. Eur Heart J 25: 728-734.

Copyright: (C2018 Didier B. This is an open-access article distributed under the terms of the Creative Commons Attribution License, which permits unrestricted use, distribution, and reproduction in any medium, provided the original author and source are credited. 